\title{
La cuestión de la proporcionalidad en la distribución del agua de riego. El caso de la acequia de Favara (huerta de Valencia)
}

\author{
Ferran Esquilache Martí \\ Universitat de València \\ ferran.esquilache@harca.org
}

\begin{abstract}
Resumen. La proporcionalidad en la distribución del agua de riego a través de partidores con tajamar es uno de los argumentos tradicionales esgrimidos para defender la continuidad en el uso y funcionamiento de los sistemas hidráulicos valencianos antes y después de la conquista cristiana del siglo XIII. En esta comunicación se intentará comprobar si verdaderamente existía una proporcionalidad entre cantidad de agua asignada y tierra regada en época andalusí, a través del ejemplo de la acequia de Favara, gracias a la identificación arqueológica de los espacios irrigados en este período y a un documento que nos informa de las medidas de sus partidores. Así mismo, se intentará comprobar si esta proporcionalidad continuó existiendo o no tras las grandes ampliaciones del sistema hidráulico realizadas tras la conquista cristiana.
\end{abstract}

Palabras Clave: Proporcionalidad, Distribución de agua, Partidores, Al-Andalus, Huerta de Valencia.

\begin{abstract}
Proportionality in the distribution of irrigation water through divisors with cutwater is one of the usual arguments to defend the continuity of the use and the working of the Valencian hydraulic systems before and after the Christian conquest of the $13^{\text {th }}$ century. This paper seeks to prove if proportionality between the quantity of water assigned and the irrigated land really existed in the Andalusi period using as example the canal of Favara. For this purpose we have archaeologically analysed the irrigated area of that period and we have studied a written document that informs about the measure of its divisors. This article is also an attempt to show if this proportionality existed or not after the extension of the hydraulic system made after the Christian conquest.
\end{abstract}

Keywords: Proportionality, Water allocation, Divisors, Al-Andalus, Huerta of Valencia.

\section{Introducción}

La proporcionalidad en la distribución del agua de riego de un río o una acequia entre sus usuarios es, probablemente, uno de los conceptos más importantes de los introducidos por Thomas F. Glick en Irrigation and Society in Medieval Valencia. Esta proporcionalidad se gestiona mediante unos partidores compuestos por un tajamar de piedra emplazado en medio del canal (conocidos en Valencia como partidors de llengua o llengïes, por la forma del tajamar acabado en un prisma triangular), que dividen el agua en partes alícuotas entre dos o más canales nuevos, de acuerdo con el tamaño del marco de sus aberturas (Fig. 1). Así, independientemente del volumen de agua que circule por una acequia, siempre será dividido con la misma proporción para cada uno de los canales que se forman, y por lo tanto con la misma proporción para cada uno de los espacios hidráulicos irrigados por cada brazo. ${ }^{1}$

Se trata de un tipo de partidor proporcional extendido por Asia, Oriente Medio y el Mediterráneo desde mucho antes de la aparición del Islam, pero probablemente fueron los musulmanes quienes lo llevaron a la península Ibérica a partir del siglo VIII, y lo usaron en sus sistemas hidráulicos para dividir el agua entre alquerías y grupos campesinos. Parece

\footnotetext{
${ }^{1}$ También existen partidores proporcionales de otros tipos, como los "peines" de las foggaras magrebíes, mucho más complejos porque de ellos parte un mayor número de canales, pero pensados para caudales mucho más reducidos que los derivados de ríos.
} 
evidente, pues, que la proporcionalidad en la distribución del agua de riego en los sistemas valencianos tiene un origen andalusí. No obstante, siguió funcionando, aparentemente, con la sociedad feudal, pues esta clase de partidores no solo continuaron existiendo en los mismos lugares donde ya estaban emplazados antes de la conquista cristiana del siglo XIII, y guardando las mismas proporciones, sino que incluso se construyeron más, tanto en ampliaciones de sistemas de origen andalusí como en sistemas hidráulicos nuevos.

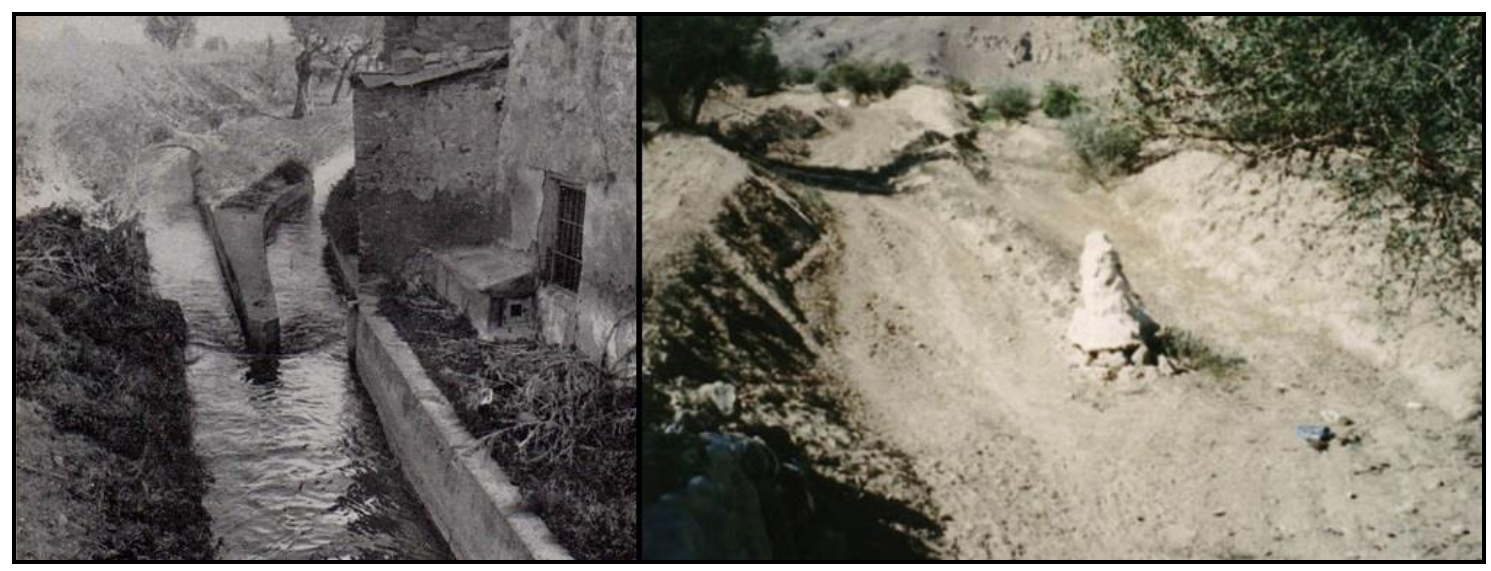

Fig. 1. A la izquierda partidor proporcional en la acequia de Tormos (huerta de Valencia) en 1956. A la derecha un partidor proporcional mucho más simple en un canal seco del valle de Hadramawt (Yemen).

De todos modos, la idea de la continuidad de la proporcionalidad en la distribución del agua de riego después de la conquista no está basada solo en el uso de partidores de lengua, pues también existe una base legal que parece recoger igualmente la costumbre anterior. Así, en primer lugar tenemos el conocido fuero del rey Jaime I en el que se regula "que prenats aqueles aygües segons que antigament és e fo establit acostumat en temps de sarrabins", y que aun siendo muy genérico es el principal argumento esgrimido por los autores que han defendido la continuidad institucional en la irrigación desde Francisco Xavier Borrull en adelante. Un argumento legal más directo para defender la proporcionalidad en la distribución de las aguas se basa en otro fuero menos conocido, donde se indica que "l'aygua de flum públich deu ésser partida segon manera e la granea de les possessions a rregar los camps". ${ }^{2}$ Sin embargo, esta segunda ley puede conducir a engaño respecto a la situación real existente después de la conquista, pues en otro lugar se establece que "los cequiers (...) façen tots los partidors de les aygües e refaçen segons la manera e l'establiment e la forma antiga". " Es decir, que los partidores debían conservar la forma y las medidas andalusíes y, por tanto, debía respetarse la misma proporcionalidad en la distribución de las aguas que ya existía antes de la conquista. Aparentemente todos estos fueros citados son complementarios, pero en realidad son contradictorios, pues suponiendo que en época andalusí ya existía la proporcionalidad, si la superficie irrigada por una acequia aumentaba después de la conquista respecto a la superficie irrigada anteriormente, pero el partidor se mantenía igual, con la misma proporción que ya estaba establecida según la superficie irrigada en época andalusí, entonces la relación entre cantidad de agua y superficie irrigada dejaba de ser proporcional, a pesar de lo establecido en el fuero XLVIII, 37. Con todo, esta contradicción tiene una explicación evidente: el fuero

\footnotetext{
${ }^{2}$ Las citas están tomadas de la compilación de fueros de Jaime I realizada en 1330 y editada por P. López Elum (2001), rúbrica XLVIII, 16 y 37.

${ }^{3}$ Ibidem, rúbrica CXLIII, 4. La redacción en catalán puede resultar un poco confusa, porque se mezcla la reglamentación de los partidores con la de los puentes, que viene a continuación, pero la redacción latina en un privilegio de 1251 que regula la actividad de los sequiers y que es previa a su integración en los Fueros romanceados no deja lugar a dudas sobre el contenido del fuero: "Et quod partitores omnes aquarum faciant et rehedificent ipsi cequiarii secundum modum, statum et formam pristinam". Publicado por J. Cortés (2001), p. 42.
} 
que establece la relación entre cantidad de agua y superficie irrigada es derecho romano, y seguramente se introdujo para los sistemas hidráulicos de nueva construcción, mientras que los dos fueros que exigen conservar las medidas y costumbres antiguas son herencia de la legislación andalusí para canales que ya existían, a pesar de los cambios físicos producidos por los añadidos y ampliaciones de la superficie irrigada (Guinot, 2008: 103-104).

También es cierto que, hasta ahora, estos razonamientos son solo conjeturas, pues es evidente que la superficie irrigada aumentó después de la conquista, pero nunca se ha podido saber cuánto. Al menos por lo que respecta a la huerta de Valencia (Guinot, 2007). Sin embargo, esto está empezando a cambiar gracias a la introducción de los métodos de la arqueología hidráulica y la interpretación morfológica, que nunca antes se habían aplicado a los grandes sistemas (Barceló, Kirchner y Navarro, 1996; Glick y Kirchner, 2000; Guinot y Selma, 2008). En los últimos años se han realizado y publicado diversos estudios sobre algunas zonas de la huerta de Valencia, y de otras huertas fluviales de menor tamaño, donde se han podido identificar espacios hidráulicos de construcción andalusí. Gracias a su estructura arborescente y a la morfología redondeada o piriforme de sus perímetros exteriores, estos se diferencian bastante bien de las ampliaciones realizadas por los feudales y los colonos cristianos; así como también de las densificaciones parcelarias con que se ocuparon los intersticios que existían entre las alquerías (qurä) antes de la conquista (Esquilache, 2011; 2012; Guinot y Esquilache, 2012). Basándose en esta metodología, pues, a continuación se intentará establecer una relación entre la proporcionalidad de los partidores y la superficie irrigada por cada uno de los brazos de la acequia de Favara (en la misma huerta de Valencia) antes y después de la conquista cristiana. Y a partir de este ejemplo comprobar si el fuero que consagra la proporcionalidad entre cantidad de agua y superficie irrigada ciertamente se cumplía.

\section{Reconstrucción de la acequia de Favara y sus partidores}

Con anterioridad a la gran expansión urbana experimentada por la ciudad de Valencia y las poblaciones de sus alrededores desde mediados del siglo XX, Favara era la acequia más larga de las del margen derecho del Turia, con más de ocho kilómetros. Y la que más superficie regaba en la huerta de Valencia -después de la Acequia Real de Montcada-, con unas 1.550 hectáreas a principios del siglo XIX, contando solo las registradas en la comuna con derecho a riego directo, y dejando de lado las ampliaciones de francs $i$ marjals, que solo recibían los sobrantes de agua si los había. Actualmente, sin embargo, apenas se conserva una pequeña parte de esta superficie, ${ }^{4} \mathrm{y}$ además muy fragmentada entra poblaciones y polígonos industriales, de manera que para su estudio ha sido necesario un trabajo previo de reconstrucción del sistema hidráulico y del parcelario asociado, realizado a partir de planos catastrales de los años 20 y 40 del siglo pasado, un plano muy exhaustivo de la propia comunidad de regantes realizado en 1917, y la fotografía aérea del llamado vuelo americano de 1956. El resultado final lo podemos ver en la Figura 2, imitando el plano de 1917.

Evidentemente, estas condiciones de conservación, que impiden la realización de un adecuado y necesario trabajo de campo, no hacen de Favara un objeto de estudio idóneo. Sin embargo, lo que hace especialmente interesante a esta acequia, para la consecución de los objetivos perseguidos en este trabajo, es que disponemos de un documento de 1362 donde

\footnotetext{
${ }^{4}$ En 2003 unas 665 ha, que son el 44\% de las existentes en el XIX (Sanchis Ibor, 2004), y que aún se han visto más reducidas en los últimos 10 años.
} 


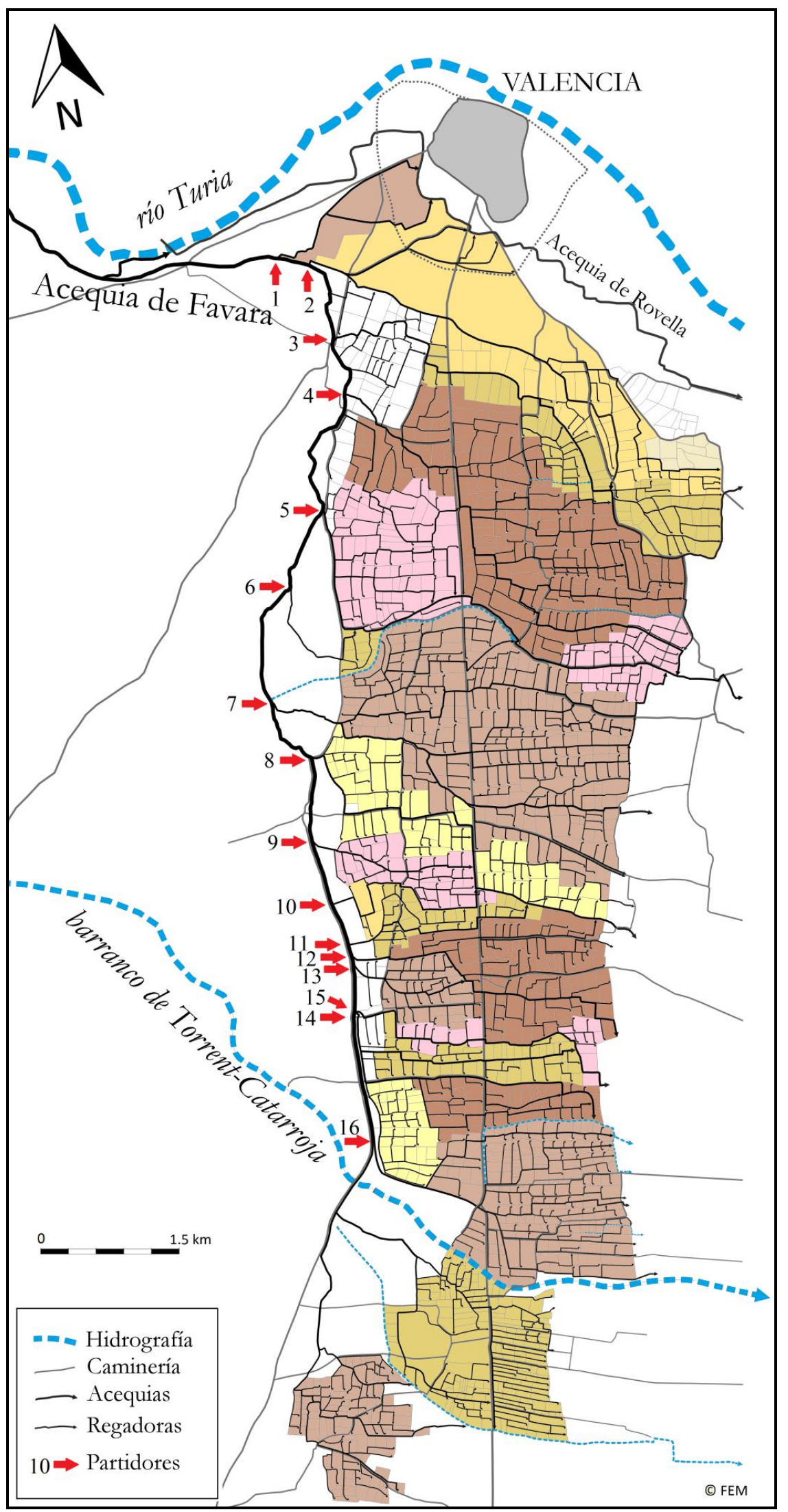

Fig. 2. Reconstrucción del sistema hidráulico de la acequia de Favara basado en un plano de 1917 
se establecen las medidas de todos los partidores situados en el canal principal de la acequia que, probablemente, aún conservaban las proporciones de época andalusí. ${ }^{5} \mathrm{La}$ comuna decidió en asamblea dejar constancia exacta de estas medidas para poder reconstruir los partidores de igual modo si eran destruidos en el futuro por algún conflicto armado (como la guerra de Castilla en aquellos mismos años), tal como establece el fuero anteriormente citado sobre las funciones del sequier. De manera que contrataron al maestro mayor de las obras de la catedral de Valencia en aquel momento, Andreu Julià, como "maestre expert en art de livellar", para que tomase las medidas y fuesen registradas ante notario. ${ }^{6}$ Por lo que respecta al contenido del documento, en la Tabla 1 pueden verse resumidas las medidas de cada partidor, con las cifras originales del documento según el sistema foral valenciano, y su traslación al sistema métrico decimal $(1$ palm $=9$ polžes $=12$ dits $=22 ’ 56 \mathrm{~cm})$.

Antes de entrar a analizar los datos debe hacerse notar que el documento no llama partidor al tajamar que divide el agua, ni al lugar donde este se sitúa como se hace en la actualidad, sino a las aberturas de los nuevos canales que se forman. Normalmente utiliza la fórmula "lo partidor qui és en la séquia major" para el marco de entrada del canal principal de Favara, y a continuación se refiere a "lo partidor menor qui és atinent d·aquell" para el marco de la entrada del brazo. Evidentemente la del brazo siempre es más pequeña que la del canal principal, excepto en el último partidor mesurado, donde la acequia madre de Favara termina oficialmente y se divide en dos brazos casi iguales. Por otro lado, debe señalarse que se trata en todos los casos de partidores proporcionales de lengua, excepto dos: el roll de la Barca y la fila de Benetússer. En el primero el documento especifica que se trata del ancho de la abertura, a la que simplemente denomina fillola, por lo que se trata de un marco de entrada cuadrangular. Por lo que respecta al otro partidor que no es proporcional, solo habla de "la gola della f[ila] qui va a Benetúcer", que está situada junto a la entrada del brazo del molino de Benetússer. También especifica que es el ancho de "la gola", por lo que se trata igualmente de un marco cuadrangular, del que además se conserva un dibujo esquemático de principios del siglo XX (Fig. 3).

Si en la Tabla 1 están las medidas de los partidores según el documento de 1362, en la Tabla 2 están los cálculos de la división del agua a partir de estas medidas. En primer lugar, en las dos primeras columnas se puede ver como se divide el agua que llega a cada partidor, de acuerdo con el tamaño de las dos aberturas. Es decir, la relación que existe entre el agua que entra a cada brazo y la que continúa por el canal principal de Favara en ese punto, tanto en porcentaje como en fracciones. En el caso de los porcentajes se ha respetado el

\footnotetext{
${ }^{5}$ Se trata de un documento bastante conocido del que se conservan hasta tres copias, pero que no ha sido bien aprovechado por ahora. La copia más antigua es de 1403 y está incluida al inicio del libro de actas de la Comuna de la acequia de Favara en el siglo XV, bajo el título de Lo inventari de la céquia de Favara. Archivo del Corpus Christi de Valencia (ACCV), Històric, VAR-201, fs. 7r-10v. Otra copia de 1456 está inserta en un pleito: Archivo del Reino de Valencia (ARV), Governació, 2288, mano 25, fs. 8r-v. T. Glick (1970: apéndice 5) publicó parcialmente esta versión. Existe una tercera copia del siglo XVI en ARV, Procesos de Madrid, H16, fs. 541v-546r. No existen discrepancias entre ellas, si bien en la copia de 1403 dice " dotze palms e mig" refiriéndose al partidor del molí de na Barcelona, y al final del documento existe un añadido realizado en 1372 en el que se explica que este partidor se midió de nuevo en dicho año porque en la copia original estaba en blanco, y que la cifra correcta es “quinze palms e mig”. En las otras dos copias está la cifra correcta en su lugar correspondiente, aunque se copia también el documento de la nueva medición realizada 10 años después. ${ }^{6}$ Aunque era habitual que los livelladors fuesen maestros canteros, tanto T. Glick (1968) como J. Torró (en prensa) han destacado la elevada categoría profesional del técnico elegido para la realización de este trabajo, aparentemente banal, de medir los partidores. Sin embargo, debe de estar relacionado con la importancia que la comuna quiso dar al documento, que se convirtió en la base legal aducida en diversos pleitos judiciales durante siglos.
} 
Tabla 1. Longitud de los partidores según el documento de 1362

\begin{tabular}{|c|c|c|c|c|c|c|}
\hline \multirow[t]{2}{*}{$\mathbf{N}^{\mathbf{o}}$} & \multicolumn{2}{|l|}{ Nombre } & \multicolumn{2}{|c|}{$\begin{array}{l}\text { Sistema de medidas foral valen- } \\
\text { ciano }\end{array}$} & \multicolumn{2}{|c|}{$\begin{array}{l}\text { Sist. Métrico Deci- } \\
\text { mal }\end{array}$} \\
\hline & s. XIV & s. XVIII-XX & Favara & Brazo & Favara & Brazo \\
\hline 1 & p. de Raiosa & fila de Rajosa & $24 \frac{1}{2}$ palm $+1 \mathrm{dit}$ & $21 / 4$ palms & $554^{\prime} 6 \mathrm{~cm}$ & $50776 \mathrm{~cm}$ \\
\hline 2 & p. del moli de na Barcelona & $\begin{array}{l}\text { brac de l'Hospital } \\
\text { o de Vintimilla }\end{array}$ & $15_{\text {dit }}^{1 / 2}$ palm $+2 \frac{1 / 2}{}$ & 3 palms $+1 / 2$ dit & $\begin{array}{l}354^{\prime} 38 \\
\mathrm{~cm}\end{array}$ & $68^{\prime} 62 \mathrm{~cm}$ \\
\hline 3 & fillola & roll de la Barca & - & $\begin{array}{l}21 / 2 \text { palms }+1 \\
\text { polze }\end{array}$ & - & $58 ’ 9 \mathrm{~cm}$ \\
\hline 4 & p. de Patraix & braç de Jesús & 15 palms - $1 \frac{1 / 2}{2}$ dits & $3 \frac{1 / 2 \text { palms }}{\text { dits }}+2$ & $\begin{array}{l}335^{\prime} 58 \\
\mathrm{~cm}\end{array}$ & $82 ’ 7 \mathrm{~cm}$ \\
\hline 5 & p. del moli d·en Conill & braç de les Monges & $15 \%$ palms & $\begin{array}{l}3 \frac{1 / 2}{\text { palm }}+1 \\
\text { polze }\end{array}$ & $\begin{array}{c}344^{\prime} 04 \\
\mathrm{~cm}\end{array}$ & $81^{\prime} 47 \mathrm{~cm}$ \\
\hline 6 & p. de Altell & fila d'Almela & 15 palms - 2 dits & $2 \frac{1 / 2}{\mathrm{palms}}+1$ & $\begin{array}{c}334^{\prime} 64 \\
\mathrm{~cm}\end{array}$ & $58 ’ 28 \mathrm{~cm}$ \\
\hline 7 & p. de la Gàbia & braç de la Gàbia & 15 palms +1 dit & $7 \frac{1 / 2 \text { palms }}{\text { dit }}+1$ & $\begin{array}{c}340^{\prime} 28 \\
\mathrm{~cm}\end{array}$ & $171^{\prime} 08 \mathrm{~cm}$ \\
\hline 8 & $\begin{array}{l}\text { p. de alqueria d.en Ramon de } \\
\text { Llibià }\end{array}$ & $\begin{array}{c}\operatorname{brac}[\text { del pont }] \\
\text { Nou }\end{array}$ & 8 palms +2 dits & ${ }_{\text {dit }}^{1 / 2 \text { palms }}+1$ & $\begin{array}{c}184^{\prime} 24 \\
\mathrm{~cm}\end{array}$ & $80^{\prime} 84 \mathrm{~cm}$ \\
\hline 9 & Comú de St. Jordi & braç d'Estadella & $101 / 2$ palms - $1 / 2$ dits & 3 palms +2 dits & $\begin{array}{c}237^{\prime} 82 \\
\mathrm{~cm}\end{array}$ & $71^{\prime} 44 \mathrm{~cm}$ \\
\hline 10 & p. de Sant Jordi & $\begin{array}{l}\text { na Picabaralla o } \\
\text { menut de St. Jordi }\end{array}$ & 11 palms - 2 dits & 2 palms - 1 dit & $244^{\prime} 4 \mathrm{~cm}$ & $43^{\prime} 24 \mathrm{~cm}$ \\
\hline 11 & $\begin{array}{l}\text { p. entre St. Jordi e de Benetús- } \\
\text { ser }\end{array}$ & braç de St. Jordi & $\begin{array}{l}11 \frac{1 / 2}{\text { palms }}-1 \frac{1}{2} \\
\text { dits }\end{array}$ & 3 palms +2 dits & $\begin{array}{c}256^{\prime} 62 \\
\mathrm{~cm}\end{array}$ & $71^{\prime} 44 \mathrm{~cm}$ \\
\hline 12 & p. de Benetúcer & braç d'Alfafar & $101 / 4$ palms & 5 palms & $\begin{array}{l}231^{\prime} 24 \\
\mathrm{~cm}\end{array}$ & $112^{\prime} 8 \mathrm{~cm}$ \\
\hline 13 & $\begin{array}{l}\text { p. entre Alfafar e molí de Be- } \\
\text { netúcer }\end{array}$ & $\begin{array}{l}\text { braç de la Cadira } \\
\text { de Benetússer }\end{array}$ & $12 \frac{1}{2}$ palms & 2 palms - 1 dit & $283 \mathrm{~cm}$ & $43^{\prime} 84 \mathrm{~cm}$ \\
\hline 14 & p. damunt lo moli de Benetúcer & $\begin{array}{l}\text { braç del Mitjà, la } \\
\text { Mola i l'Orba }\end{array}$ & 11 มू palm & 4 palms +2 dits & $\begin{array}{c}252^{\prime} 67 \\
\mathrm{~cm}\end{array}$ & $94 \mathrm{~cm}$ \\
\hline 15 & fila de Benetússer & fila de Benetússer & - & $3 / 4$ palm & - & $16^{\prime} 92 \mathrm{~cm}$ \\
\hline 16 & $\begin{array}{l}\text { p. per on va aygua a Albal }+ \\
\text { partidor de Maçanaça }\end{array}$ & $\begin{array}{c}\text { braç d'Albal i } \\
\text { Catarroja + braç } \\
\text { de Massanassa }\end{array}$ & 5 ga palm & $5+3 / 4$ palms & $\begin{array}{c}117 ’ 31 \\
\mathrm{~cm}\end{array}$ & $129 ’ 72 \mathrm{~cm}$ \\
\hline
\end{tabular}




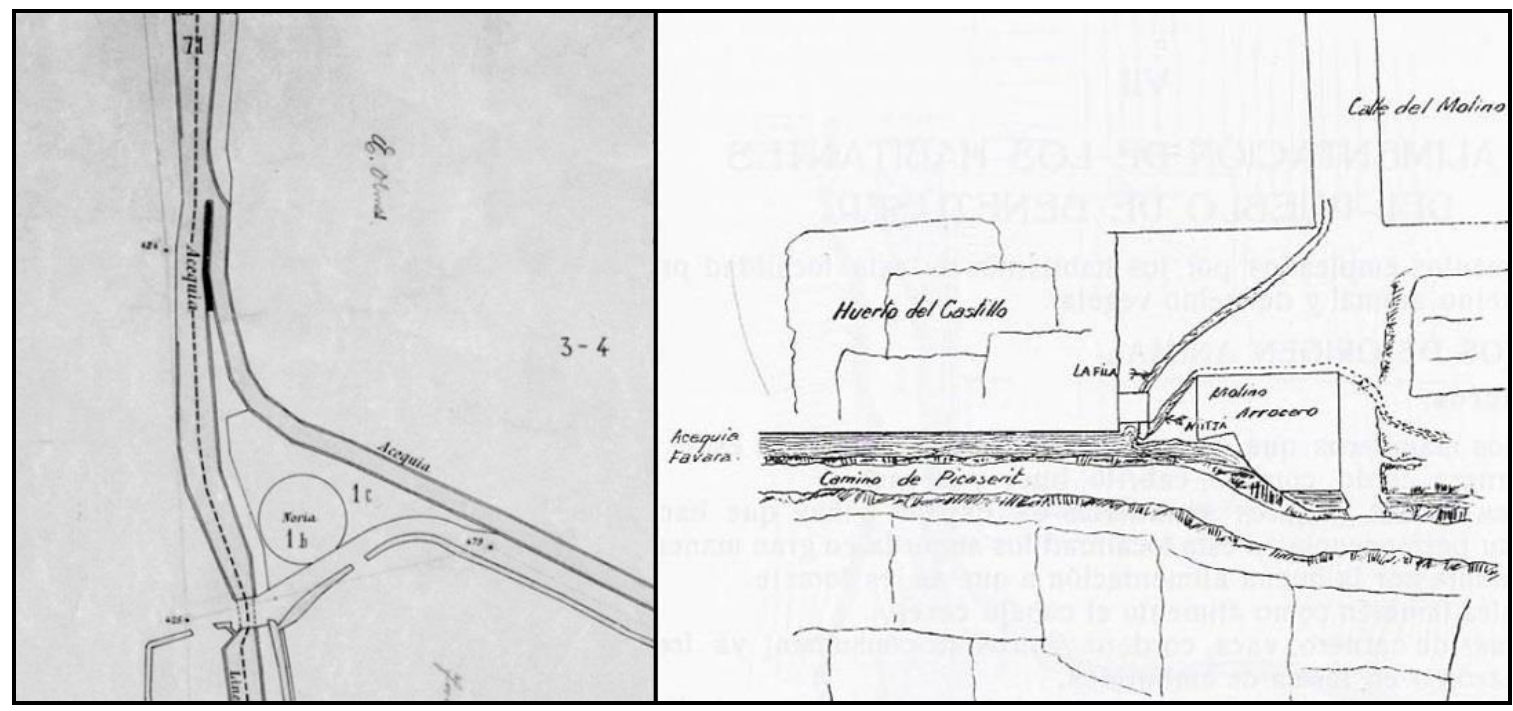

Fig. 3. A la izquierda el partidor proporcional de lengua del braç d'Estadella, en un plano catastral de los años 40 del siglo XX. A la derecha la lengua del braç del Mitjà, situada justo antes del molino de Benetússer, en un dibujo realizado por Vicente Navarro Soler en 1927. Junto a este partidor está situada la entrada de la fila de Benetússer, sin tajamar, y con la caseta moderna del torno situada sobre de ella.

resultado exacto del cálculo realizado, dejando los decimales para que se pueda apreciar que en la inmensa mayoría no se trata de números enteros como cabía esperar. En la columna de las fracciones, sin embargo, se han redondeado para representar las partes alícuotas en las que, aparentemente, los constructores querían dividir el agua, aunque estas no sean exactamente las reales.

Tabla 2. División del agua en los partidores de acuerdo con el documento de 1362

\begin{tabular}{|c|c|c|c|c|c|c|c|}
\hline \multirow{2}{*}{$\mathbf{N}^{\mathbf{o}}$} & \multirow{2}{*}{$\begin{array}{c}\text { Nombre } \\
\text { contemporáneo }\end{array}$} & \multicolumn{2}{|c|}{$\%$ en el partidor } & \multicolumn{2}{|c|}{ Fracción en el partidor } & \multicolumn{2}{|c|}{$\%$ del total de acequia } \\
\hline & & Brazo & Favara & Brazo & Favara & Brazo & Favara \\
\hline 1 & fila de Rajosa & $8 ’ 4 \%$ & $91^{\prime} 6 \%$ & $1 / 12$ & $11 / 12$ & $8{ }^{\prime} 4 \%$ & $91 ' 6 \%$ \\
\hline 2 & braç de l'Hospital & $162 \%$ & $83 ' 8 \%$ & $1 / 6$ & $5 / 6$ & $14^{\prime} 9 \%$ & $76{ }^{\prime} 8 \%$ \\
\hline 3 & roll de la Barca & - & - & - & - & - & - \\
\hline 4 & braç de Jesús & $19^{\prime} 8 \%$ & $80^{\prime} 2 \%$ & $1 / 5$ & $4 / 5$ & $14^{\prime} 6 \%$ & $62 ’ 7 \%$ \\
\hline 5 & brac de les Monges & $19 ’ 1 \%$ & $80 ’ 9 \%$ & $1 / 5$ & $4 / 5$ & $11^{\prime} 9 \%$ & $50{ }^{\prime} 3 \%$ \\
\hline 6 & fila d'Almela & $15 \%$ & $85 \%$ & $3 / 20$ & $17 / 20$ & $7 ’ 5 \%$ & $42 ’ 8 \%$ \\
\hline 7 & braç de la Gàbia & $333^{\prime} \%$ & $66,5 \%$ & $1 / 3$ & $2 / 3$ & $143 \%$ & $28{ }^{\prime} 4 \%$ \\
\hline 8 & braç Nou & $30{ }^{\prime} 5 \%$ & $69 ’ 5 \%$ & $3 / 10$ & $7 / 10$ & $897 \%$ & $19^{\prime} 8 \%$ \\
\hline 9 & brac d'Estadella & $23 ’ 1 \%$ & $76{ }^{\prime} 9 \%$ & $2 / 9$ & $7 / 9$ & $4^{\prime} 6 \%$ & $15 ’ 2 \%$ \\
\hline 10 & braç de na Picabaralla & $15 \%$ & $85 \%$ & $3 / 20$ & $17 / 20$ & $23^{\prime} 3 \%$ & $12^{\prime} 9 \%$ \\
\hline 11 & braç de Sant Jordi & $21{ }^{\prime} 8 \%$ & $78{ }^{\prime} 2 \%$ & $2 / 9$ & $7 / 9$ & $2{ }^{\prime} 8 \%$ & $10^{\prime} 1 \%$ \\
\hline 12 & brac d'Alfafar & $32 \% 8 \%$ & $67^{\prime} 2 \%$ & $1 / 3$ & $2 / 3$ & $3,3 \%$ & $6{ }^{\prime} 8 \%$ \\
\hline 13 & brac de la Cadira & $13 ’ 5 \%$ & $86 ’ 5 \%$ & $2 / 15$ & $13 / 15$ & $099 \%$ & $5 ’ 9 \%$ \\
\hline 14 & fila de Benetússer & - & - & - & - & - & - \\
\hline 15 & braç del Mitjà i l'Orba & $27 ’ 1 \%$ & $72 ’ 9 \%$ & $4 / 15$ & $11 / 15$ & $1 ' 6 \%$ & $4{ }^{\prime} 3 \%$ \\
\hline 16 & $\begin{array}{l}\text { brac de Massanassa + } \\
\text { braç d'Albal-Catarroja }\end{array}$ & $52 ’ 5 \%$ & $47 ’ 5 \%$ & $1 / 2$ & $1 / 2$ & $2 ’ 3 \%$ & $2 ’ 2 \%$ \\
\hline
\end{tabular}


Sobre esto, el caso de Gàbia es el ejemplo más claro: 1/3 del agua que llegaba a este partidor entraba en el brazo, y 2/3 seguía por el canal principal de Favara, que aún continuaba hacia el sur. Esta división, expresada en porcentajes, debería ser de un 33'33\% para el brazo y un $66^{\prime} 66 \%$ para el canal de Favara, y, sin embargo, el resultado es $333^{\prime} 5 \%$ y $66^{\prime} 5 \%$ respectivamente. Así, el brazo está ligeramente favorecido con medio dedo más de los que debería tener para que existiese una proporcionalidad exacta de $1 / 3$. También es cierto que medio dedo foral valenciano son solo 9'4 milímetros, por lo que esta divergencia en la división lógica del agua podría deberse a diversos factores. Por ejemplo a un leve movimiento de las piedras por la presión del agua a los largo de los siglos, o bien a una medición incorrecta por parte del livellador, aunque en ambos casos se trata de explicaciones poco probables. El desgaste de la piedra por la fricción continua del agua es más factible, aunque casi un centímetro parece demasiado, por lo que es más probable que la abertura del brazo fuese ligeramente favorecida desde el principio, alterando la proporción, porque este tendría menos tiro. De hecho, una vez pasado este partidor el canal de Favara seguía recto, y el agua tendería a entrar en él por la fuerza de la inercia, mientras que el brazo tenía una curva muy cerca de la entrada, porque rápidamente giraba hacia el sureste, frenando aún más la velocidad del agua y por tanto la cantidad que entraba por el brazo. En consecuencia, si las dos aberturas del partidor a cada lado del tajamar hubiesen tenido una división exacta de $1 / 3$ y $2 / 3$ respectivamente, el agua no se hubiese dividido verdaderamente en esta proporción, porque por una de las aperturas entraba el agua a mayor velocidad y por lo tanto en mayor cantidad. Por eso se necesitaba favorecer al lado con menos tiro, aumentando levemente su anchura. ${ }^{7}$ Lo cierto es que en todos los partidores uno de los lados está favorecido con algunos milímetros respecto a la verdadera proporción que deberían tener, excepto dos que, como luego veremos, son posteriores a la conquista (nota 12).

Si en las dos primeras columnas de la Tabla 2 podemos ver como se reparte el agua que llega a cada partidor, en la tercera columna se presenta, solo en porcentaje, la cantidad de agua que toma cada brazo en relación a toda la que entra en la acequia por el azud. O lo que es lo mismo, toda la que existe antes de la derivación del primer partidor. Y en la subcolumna del canal de Favara se presenta el porcentaje de agua total de la acequia que queda en cada partidor para los brazos siguientes, una vez descontada la proporción de agua tomada por cada uno de los brazos anteriores. Para entenderlo mejor veamos de nuevo el ejemplo de Gàbia. Si ya hemos visto que este brazo tomaba un 33’5\% del agua que llegaba a su partidor, en realidad estaba tomando un $14{ }^{\prime} 32 \%$ del agua total de la acequia, y además en ese punto del canal principal de Favara quedaba un $28,43 \%$ del agua total, que continuaría para ser repartida entre los diez siguientes brazos. En el último partidor, donde termina oficialmente la acequia de Favara, al brazo de Massanassa ya solo le quedaría un 2’3\% del agua total, y al de Albal-Catarroja un 2'2\%.

Por otro lado, es necesario advertir que, necesariamente, las proporciones de esta tercera columna no son del todo reales, debido a la existencia de los dos partidores antes mencionados que no son de lengua. También existía una proporción en estas dos tomas, pero como la entrada del agua era lateral, y no de frente como en los partidores que cuentan con tajamar, frenando la velocidad del agua que entra, y además desconocemos el ancho de la acequia madre en ese punto, resulta imposible calcular qué proporción de agua entraba por estos dos brazos. En consecuencia, al no poder tener en cuenta el agua que entra por estos dos brazos, el porcentaje asignado a los demás está por encima del real. Si bien, como se

\footnotetext{
${ }^{7}$ Sobre esto véase lo que argumenta uno de los procuradores en un pleito del siglo XV entre usuarios de la acequia de Mestalla en T. Glick (1970: 92-93). A veces podía estar favorecido uno de los lados del partidor si el otro canal tenía más pendiente, pues esto también hacía aumentar la velocidad del agua.
} 
distribuye proporcionalmente entre todos ellos, y tampoco existe una solución a este problema, esta pequeña distorsión resulta estadísticamente aceptable.

Entrando ya a analizar el contenido de las tablas, evidentemente las proporciones de las dos primeras columnas no tienen un especial interés para el objetivo que ahora nos ocupa. Aunque son necesarias para calcular las proporciones de la tercera columna, que es la que necesitamos. Centrándonos en ella, pues, como podemos observar los brazos que se llevan una mayor cantidad de agua del total disponible son los de l'Hospital-Sant Jeroni, Jesús y la Gàbia, con un poco más del 14\% cada uno. De hecho, en efecto, son los que más superficie irrigaban, como veremos más adelante. Por el contrario, es evidente que los últimos brazos presentan una dotación de agua muy escasa, que ni siquiera llega al 1\% en el caso de la Cadira de Benetússer, a pesar de irrigar una superficie mayor a la de otros brazos anteriores. De hecho, a partir del Braç Nou apenas quedaba ya un $20 \%$ del agua total de la acequia para repartir entre el resto de brazos, que aún eran nueve.

Como ya hemos visto, la acequia de Favara era una de las más largas de la huerta de Valencia, e irrigaba una gran superficie, por lo que sus brazos finales siempre fueron deficitarios, especialmente en verano y en épocas de sequía, cuando el volumen de agua disminuía (Glick, 1970: 81-82). No obstante, la distribución del agua de Favara que se presenta en la tercera columna de la Tabla 2 no sería factible y, de hecho, nunca existió de esta manera. Los partidores de los brazos de la parte norte (desde Rajosa al Braç Nou) eran corribles, lo que significa que siempre estaban abiertos y siempre entraba agua en sus brazos; mientras que el resto de partidores del sur (desde $\mathrm{Na}$ Estadella hasta Albal) se turnaban el agua entre ellos, de manera que solo el brazo que tenía el turno estaba abierto para que entrase toda el agua, mientras los otros permanecían cerrados. Esto se establece en el capítulo XXXI de las Ordenanzas aprobadas en 1446, las más antiguas que se conservan, que dice así:

Ítem, declaram que los que deuen ésser entre si atandats són los infra següents: ves lo partidor de na Stadella, e lo partidor apellat de na Picabaralla, e lo partidor de Sent Jordi, e quatre caffisades en la alqueria [que] solia ésser d·en Passadores, e la alquer[i]a dels Regans, [e] la cadira de la carrera Orba, son de la tanda del disabte; e Benetúcer és de la tanda del diumenge; e lo partidor de Alffaffar e de Sedaví, e la cadira [d] e Bene[tú]çer són de la tanda de dilluns e dels dimarts; e M[a]çanaça e Catarroga e Albal són de la tanda de $d\left[\right.$ imecr] es e del dijous e del divendres tro al sol exit lo d[i] sapte. ${ }^{8}$

De acuerdo con este capítulo, es evidente que las medidas y proporciones de los partidores de lengua en los brazos que se turnan semanalmente el agua no son tan importantes como en los partidores corribles, en los que la anchura de las entradas a cada lado del tajamar es la base en la que se fundamenta la distribución proporcional del agua total de la acequia. Por lo que respecta al contenido del mismo, evidentemente los días asignados están en relación con los núcleos de población, y no tanto con los brazos existentes. Benetússer los domingos, Alfafar y Sedaví los lunes y martes, y Massanassa, Catarroja y Albal los miércoles, jueves, y viernes, de manera que tenían un día de agua para cada pueblo independientemente de la superficie irrigada por cada brazo. Los sábados, por el contrario, son para los brazos que no se relacionan directamente con un núcleo habitado, que en otras acequias como Montcada denominan deserts.

Por otro lado, resulta especialmente interesante que el turno semanal descrito empiece en sábado (costumbre que aún se conservaba en el siglo XVIII, como indican las Ordenanzas

${ }^{8}$ ACCV, Històric, VAR-201, fs. 18r-v. Donde dice Cadira de Benetússer se refiere, necesariamente, a la Fila. En las ordenanzas de 1701 éste es el capítulo 122, y es prácticamente igual, aunque cambian los nombres de las alquerías del sábado y se añaden otras nuevas. Estas ordenanzas están publicadas en el tomo 2 de la traducción castellana de la obra de F. Jaubert de Passà, Canales de riego de Cataluña y reino de V alencia. 
aprobadas en 1701), que es el primer día de la semana para los musulmanes. Y que el último día del turno sea el viernes, que es también el día que le toca al último brazo de la acequia de Favara. Del mismo modo, el turno diario empieza con la salida del sol, y termina con la salida del sol del día siguiente, como es habitual en los sistemas hidráulicos de todo el mundo musulmán. Todo ello nos viene a indicar que la práctica de este turno semanal (en árabe dawla o dawr) es anterior a la conquista cristiana, y que siguió funcionando después de ésta, de acuerdo con lo establecido en las ordenanzas de la Comuna, que a su vez seguían lo establecido en los Fueros.

\section{La acequia de Favara en época andalusí y su proporcionalidad}

En la Figura 4, donde aparece representada la reconstrucción del sistema hidráulico de Favara y su parcelario asociado, puede verse una propuesta de identificación de espacios hidráulicos andalusíes, realizada mediante la interpretación morfológica del conjunto del sistema y su parcelario. En un trabajo anterior ya se ha justificado metodológicamente esta propuesta y se ha argumentado al respecto de una forma más extensa, permitiendo que no sea necesario entrar ahora en ella por cuestiones de espacio (Esquilache, en prensa). Desgraciadamente el espacio cultivado inmediato a algunas de las poblaciones desapareció hace tanto tiempo que no se conservan registros cartográficos históricos que permitan una reconstrucción adecuada, por lo que no se han podido identificar todas las huertas andalusíes que sabemos que existían por estar documentada su alquería, como es el caso de Rajosa y de Sedaví. Si bien, por el contrario, se han podido identificar diversos espacios hidráulicos de alquerías que ya sabíamos que existían por esta misma razón, pero que no sabíamos dónde estaban exactamente, como por ejemplo Malilla, Altell, Gàbia, Orba o Benimassot. En la Figura 5 puede verse su emplazamiento exacto, junto a sus nombres, dibujados en un plano de forma aislada respecto al parcelario construido después de la conquista cristiana sobre los intersticios no irrigados en época andalusí. Esto es, tal y como sería el sistema hidráulico a principios del siglo XIII, justo antes de la llegada de los conquistadores cristianos, de acuerdo con esta propuesta de identificación.

Viendo la Figura 5, y de acuerdo con los nuevos conocimientos aportados en los últimos años por la arqueología hidráulica, es evidente que la huerta de Valencia -probablemente igual que el resto de huertas fluviales mediterráneas-, no era en época andalusí tal y como la conocemos actualmente o desde que existe memoria histórica. Y todo parece indicar que su transformación más importante, más allá de su fundación y desarrollo primigenio, se produjo a mediados del siglo XIII, tras la conquista y colonización catalano-aragonesa. Pero esto no significa que la etapa andalusí fuese monolítica, o que estuviese al margen de la evolución histórica. Así pues, en el caso de la acequia de Favara, además de la propuesta de identificación de espacios hidráulicos andalusíes, también se ha realizado una propuesta de periodización de la construcción y desarrollo del sistema en diversas fases -desde su fundación hasta que la sociedad andalusí desapareció en Valencia por la conquista- basada en la estructura del sistema hidráulico.

De acuerdo con esta propuesta, existiría una primera fase, la más antigua, que podemos relacionar con el núcleo central de alquerías formado por los espacios hidráulicos de Patraix (Batrāyr al-Fawqīya y Batrāyr as-Saflìya), Malilla (<Malīla) y Altell (<al-Tell). Total cuatro huertas regadas por dos brazos, que a su vez de subdividían mediante partidores de lengua, iguales a los que ya hemos visto emplazados sobre la acequia madre, y que conducían el agua hasta cada uno de estos espacios hidráulicos identificados. Debe señalarse que este tramo de la acequia de Favara es, precisamente, el menos recto de todo el recorrido, pues, 
además de cruzar varios barrancos, no fue diseñado inicialmente para ser un canal largo, sino solo uno de los diversos brazos que llegaban hasta aquí. En definitiva, aunque por el momento no existe ninguna datación sobre el origen de la acequia, es plausible proponer que estos serían los asentamientos primigenios de los grupos campesinos que construyeron el azud y el primer tramo de la acequia de Favara, los cuales pertenecían a tribus imazighen de la confederación Hawwāra que le dieron nombre. ${ }^{9}$

Una segunda fase correspondería al resto de la acequia hacia el sur, a partir del antiguo barranco de la Rambleta, que incluye las alquerías de Gàbia ( $<$ Gawiyar) y Benimassot $(<$ Banī Mas'ūd) compartiendo un mismo brazo, el grupo formado por Benetússer ( $<$ Banī Tuzarî), Sedaví ( $<$ Banī Sīdabî), Alfafar (<al-Hūfar) y Orba ( $<$ Awraba); y finalmente Massanassa (<Manzil Nașr), Catarroja (<Qat'a ar-Ruaya) y Albal (<al-Ba'l), este último con dos espacios hidráulicos, uno de los cuales responde al nombre de Benimà (posiblemente Banī Ahmad, aunque no es muy seguro). Además, parece que hay un răhal, el de Abinmopherez ( $<$ Ibn Mufarriŷ) que aparece citado en el Repartiment como donación a la orden catalana de

${ }^{9}$ Los Hawwāra son un pueblo o confederación de tribus bereberes (como por ejemplo la tribu Malīla, que da nombre a la alquería de Malilla) que tiene su origen en la actual Libia, y que se extendieron por todo el Mediterráneo a partir del siglo VII, incluidos Sicilia y Al-Andalus desde el primer momento de la conquista del siglo VIII. T. Lewicki (1979). Para el caso concreto del Sharq al-Andalus véase P. Guichard (1969). 


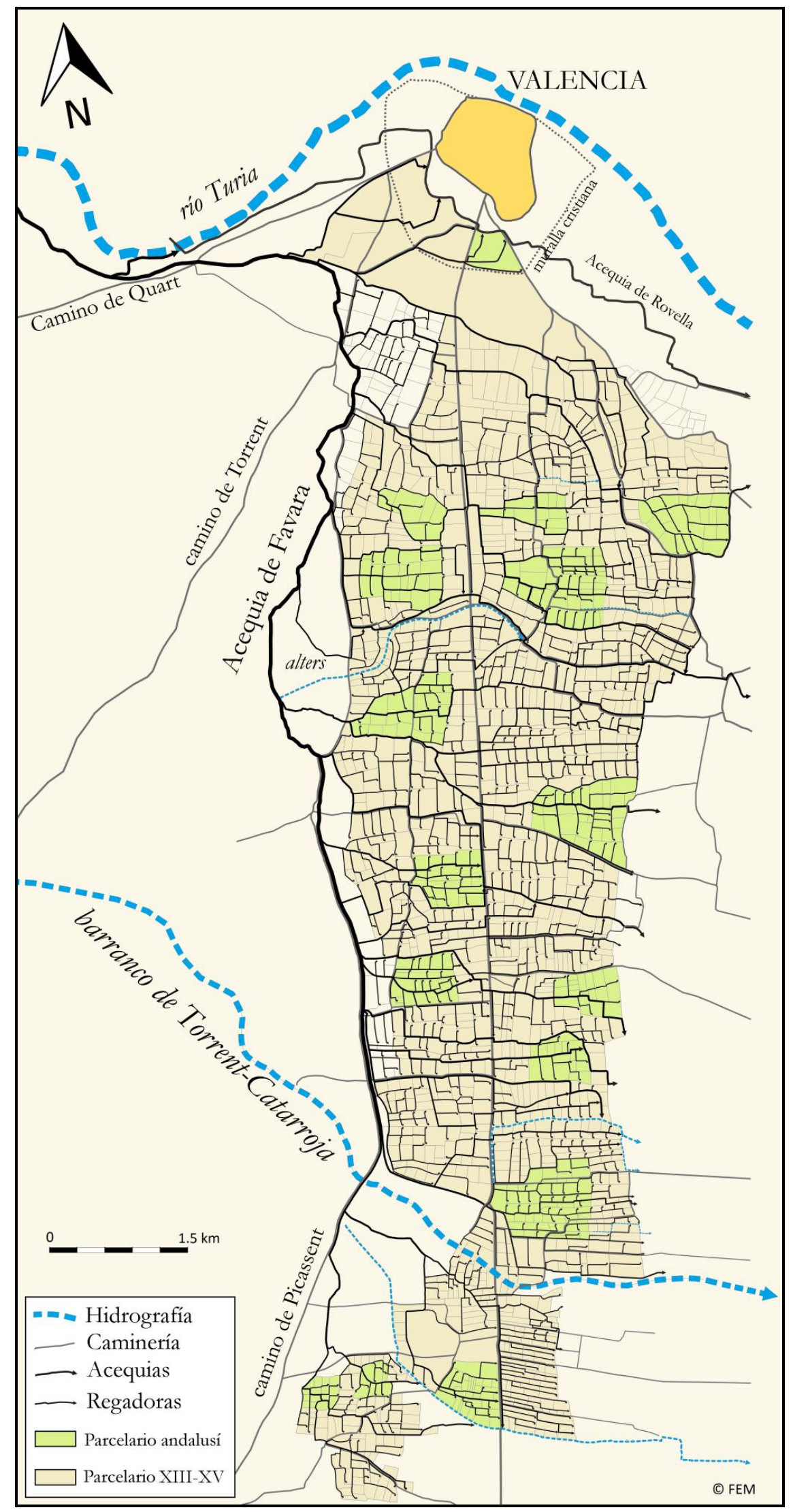

Fig. 4. Reconstrucción del sistema y el parcelario de Favara con identificación de espacios andalusíes. 


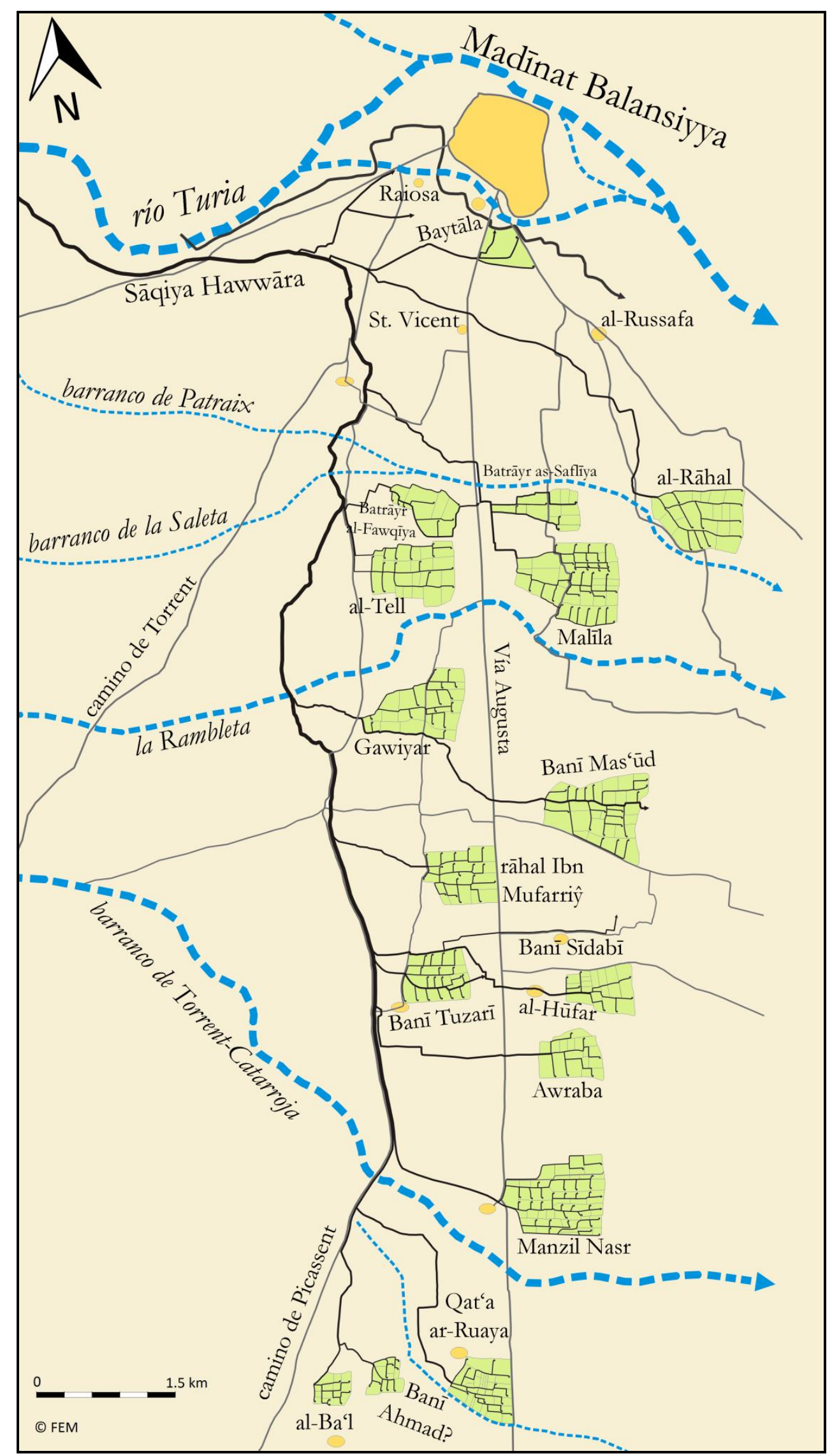

Fig. 5. Reconstrucción de los espacios irrigados por la acequia de Favara en época andalusí. 
Sant Jordi d'Alfama, que es quien probablemente dio nombre al brazo de Sant Jordi. ${ }^{10}$ Con todo, esta segunda fase podría haber sido construida en diversas subfases: la de Gàbia y Benimassot por un lado, la del grupo de Benetússer, Sedaví, Alfafar y Orba por otro, posiblemente la de Massanassa en tercer lugar, y finalmente la de Albal y Catarroja, pasado el barranco de Torrent. Aun así, si estas subfases existieron, no debieron ser muy dilatadas en el tiempo, aunque esto último solo es una hipótesis que de momento no puede justificare solo con la morfología del sistema. En cualquier caso, de acuerdo con las excavaciones arqueológicas realizadas en Benetússer y Alfafar, esta segunda fase de construcción de Favara se puede datar entre finales del siglo IX y principios del X (Escribà y Barceló, 1990).

Finalmente, habría una tercera fase, que necesariamente está ligada al aumento del poder del Estado y al desarrollo urbano de Madīnat Balansiyya a partir de un momento histórico determinado. Consistió en la construcción de brazos nuevos añadidos al inicio del sistema, e implica la aparición de espacios hidráulicos asociados a arrabales urbanos o semi-rurales, como Rajosa y la Boatella (<Baytāla), y lo que parece ser el rāhal de Abinxalveto $(<\mathrm{Ibn}$ Shalbat), también conocido como Qaryat al-Rāhal, aunque la relación de este espacio hidráulico con este topónimo del Repartiment no sea muy segura. De hecho, se trata de la zona más cercana a Valencia, y por tanto la primera en desaparecer por el avance de la urbanización de la ciudad; primero en el siglo XIV con la nueva muralla de Pedro el Ceremonioso y más tarde en el XIX con el Ensanche y las vías del tren, de manera que es la zona de interpretación más difícil y es posible que hubiese más espacios hidráulicos que no se han podido identificar, empezando por el de Rajosa. En cualquier caso esta tercera fase fue muy tardía, pues solo se puede datar hacia finales del siglo XII, de acuerdo con las excavaciones arqueológicas realizadas en el brazo del Hospital que llevaba el agua a la Boatella (Burriel y Rosselló, 2002: 9-10).11

En definitiva, como podemos observar, las fases propuestas coinciden, aproximadamente, con las dos mitades en las que se dividía la acequia entre brazos corribles, o de agua continua, y brazos con turno semanal. Es decir, que las alquerías más antiguas, fundadoras del sistema, más los arrabales de la ciudad auspiciados por el estado, tenían agua siempre. Mientras que el resto de alquerías rurales, que eran asentamientos de grupos campesinos que llegaron más tarde, seguramente en época del Califato, eran los que debían turnarse el agua. Así pues, si descartamos de la lista de partidores de 1362 los seis brazos en los que no se ha identificado ningún espacio hidráulico andalusí, porque fueron añadidos después de la conquista cristiana para regar los intersticios entre alquerías, ${ }^{12}$ los once brazos que nos quedan son los que podemos ver en la Tabla 3.

En la primera columna se pueden distinguir los brazos que tienen agua continua (corribles) y los que no, indicándose el día que les corresponde en el segundo caso. En las dos siguientes columnas podemos ver las proporciones de agua del total de la acequia que corresponden a cada uno de los brazos, en porcentaje y en fracciones, que son las que se derivan de las medidas de sus partidores como en la tercera columna de la Tabla 2. Pero aquí sin contar las sangrías de los brazos añadidos posteriormente, de manera que, si no existe ningún error, estas deberían ser las proporciones de agua que correspondían a cada brazo al final

\footnotetext{
10 "Frater Geraldus de Prato, comendator de Alfama, raallum Abinmoerez et domos et ortum", (23-8-1238). A. Ferrando, 696; Cabanes-Ferrer, Rep I: 707.

${ }^{11}$ El canal principal de Favara, sin embargo, como es bien sabido, ya está documentado a finales del siglo XI por Ibn 'Idhārī en el Al-Bayān al-Mughrïb. Sobre la relación entre los espacios hidráulicos identificados y los topónimos con los que se relacionan, y sobre las diversas fases de construcción aquí propuestas de forma escueta, véase F. Esquilache (en prensa).

${ }^{12}$ Los brazos añadidos son: (3) el roll de l'alqueria de la Barca, (6) la fila d'Almela o d'Altell, (8) el braç del pont Nou, (10) el braç de na Picabaralla o menut de Sant Jordi, (11) el braç Sant Jordi, y (14) la fila de Benetússer.
} 
del período andalusí, justo antes de la conquista del siglo XIII. En cualquier caso, del mismo modo que en la tabla anterior, en los porcentajes se ha respetado el resultado exacto del cálculo realizado, incluyendo los decimales, pero se han redondeado las fracciones para evitar las medidas de corrección introducidas por los constructores de los partidores con la intención de suplir la diferencia de velocidad del agua entre canales rectos y curvos, o entre canales con una pendiente diferente.

Respecto a la partición del agua de la acequia de Favara en 24 partes iguales, esto tiene una explicación. Viendo solo los porcentajes lo primero que llama la atención es que a los brazos que se turnan el agua les corresponde un 33'1\% del total de la acequia de Favara, es decir, redondeando, 1/3. Esta división se produce en el partidor de la Gàbia, que es el último corrible, y recordemos que en este punto el brazo recibía $1 / 3$ del agua que llegaba al partidor y el canal principal recibía $2 / 3$ para el resto de brazos. Así pues, si $2 / 3$ del agua que llega al partidor son $1 / 3$ del agua total de la acequia, eso quiere decir que el brazo de la Gàbia recibía 1/6 del agua total de la acequia, y el canal principal 2/6 para los brazos no corribles. En consecuencia, es evidente que la distribución del agua de Favara está basada en una partición en 6 partes iguales o en cualquiera de sus múltiplos. Y de todos ellos el 24 es el más pequeño en el que todas las fracciones están formadas por números enteros. ${ }^{13}$

Tabla 3. Alquerías y superficie irrigada por la acequia de Favara en época andalusí

\begin{tabular}{|c|c|c|c|c|c|c|c|}
\hline $\mathbf{N}^{\mathbf{o}}$ & $\begin{array}{c}\text { Nombre actual } \\
\text { de los brazos }\end{array}$ & $\begin{array}{c}\text { Turno } \\
\text { semanal }\end{array}$ & $\begin{array}{c}\% \\
\text { agua }\end{array}$ & $\begin{array}{c}\text { Fracción } \\
\text { agua }\end{array}$ & $\begin{array}{l}\text { Alquerías } \\
\text { andalusíes }\end{array}$ & $\begin{array}{l}\text { Hectáreas reales } \\
\text { según propuesta }\end{array}$ & $\begin{array}{l}\text { Hectar. } \\
\text { teóricas }\end{array}$ \\
\hline 1 & braç de Rajosa & corrible & $8 \% 4 \%$ & $2 / 24$ & Raiosa & [?] & 27 \\
\hline 2 & brac de l'Hospital & corrible & $14^{\prime} 9 \%$ & $3,5 / 24$ & Baytāla + al-Rāhal & $8+25=33$ & 46 \\
\hline 4 & braç de Jesús & corrible & $15{ }^{\prime} \%$ & $35 / 24$ & Batrāyr + Malīla & $12+33=45$ & 46 \\
\hline 5 & brac de les Monges & corrible & $11^{\prime} 7 \%$ & $3 / 24$ & Batrāyr + al-Tell & $11+21=32$ & 40 \\
\hline 7 & braç de la Gäbia & corrible & $167 \%$ & $4 / 24$ & Gawiyar + Banī Mas'ūd & $23+30=53$ & 53 \\
\hline 9 & brac d'Estadella & Sáb & \multirow[b]{2}{*}{$\uparrow$} & \multirow[b]{2}{*}{$\uparrow$} & Kar & 18 & \multirow{2}{*}{$\uparrow$} \\
\hline 12 & brac d'Alfafar & anes y Martes & & & Banī Sīdabī + al-Ḥūfar & {$[?]+13$} & \\
\hline 13 & braç de la Cadira & Domingo & \multirow{2}{*}{$33 ’ 1 \%$} & \multirow{2}{*}{$8 / 24$} & Banī Tuzarī & 16 & \multirow{2}{*}{106} \\
\hline 15 & b. Mitjà-Mola-Orba & Sábado & & & Awraba & 11 & \\
\hline \multirow{3}{*}{16} & brac de Massanassa & Miércoles & $\downarrow$ & & Manzil Nașr & 33 & \\
\hline & b. Catarroja i Albal & Jueves y Viernes & $\downarrow$ & $\downarrow$ & Qat'a ar-Ruaya +al-Ba'l & $16+(6+6)=28$ & \\
\hline & Total Favara & & $100 \%$ & $24 / 24$ & & $282+[?]$ & 318 \\
\hline
\end{tabular}

En la cuarta columna de la Tabla 3 también se han indicado las alquerías asociadas a cada brazo, y en la quinta la superficie aproximada que se regaba en época andalusí por cada uno de ellos, que es la suma de los diversos espacios hidráulicos identificados (de acuerdo con la propuesta de la Figura 5). Como la gran mayoría ya han desaparecido, su superficie se ha medido mediante un SIG, superponiendo la fotografía aérea de 1956 sobre la ortofotografía actual. Es por ello que, necesariamente, la cifra indicada debe considerarse aproximada. Finalmente, en la última columna están las hectáreas teóricas que debería regar ca-

\footnotetext{
${ }^{13}$ Excepto dos que no lo son, l'Hospital y Jesús, que tienen 3'5 partes cada uno, aunque también es una partición lógica. En realidad también puede dividirse en 48 partes, o en 144, etc., pero de esta manera coincide con las 24 partes o qirats en que se dividen todos los partidores en la Ghuta de Damasco. Y también coincide con la propuesta horaria de Glick sobre las "filas" valencianas en tiempos de sequía, si bien no tiene sentido una conversión de las partes de cada brazo en horas de agua en un turno de 1 día (24h.) para todos los brazos corribles, cuando el turno de los no corribles es semanal. Sería necesario dividir el agua en 168 partes, que serían las necesarias para una semana. En cualquier caso no parece que esto fuese necesario, incluso con sequía extrema, para la superficie total irrigada en época andalusí. Sobre este tema véase T. Glick (1970: 207-213).
} 
da brazo, de acuerdo con la parte alícuota de agua que le corresponde, si verdaderamente existía una proporcionalidad entre cantidad de agua y superficie irrigada. Para calcularlo se ha tomado como referencia el brazo de Gàbia, partiendo del hecho que es, de los corribles, el que cuenta con los espacios hidráulicos con una estructura y una morfología más claras, y que su superficie también es de las más seguras porque uno de ellos aún se conserva parcialmente. En consecuencia, sabiendo que regaba 53 hectáreas y tenía 4/24 partes de agua, mediante una regla de tres simple se calcula fácilmente la superficie total teórica irrigada por Favara en época andalusí: 318 hectáreas. Y a partir de esta cifra se calcula mediante la misma operación matemática la superficie teórica irrigada por cada uno de los brazos.

Si el procedimiento y los cálculos son correctos, esto nos permite saber ahora que el brazo de Rajosa debía regar aproximadamente unas 27 hectáreas, aunque nos sea imposible actualmente reconstruir e identificar su espacio hidráulico. La superficie asignada al brazo de Jesús (46 ha) coincide bastante bien con las superficie identificada realmente para las alquerías de Patraix de Abajo y Malilla (45 ha). Teniendo en cuanta, pues, que la superficie real identificada es aproximada por el método de medición, y que tampoco es probable que en época andalusí existiese una relación proporcional perfecta entre parte alícuota de agua y superficie irrigada, parece evidente que, en relación al brazo de Gàbia, sí existía una proporcionalidad. En el caso de l'Hospital-Sant Jeroni las superficies no encajan tan bien, pues hay una diferencia de 13 hectáreas entre las propuestas para la Boatella y Alarhal (33 ha) y las que debería tener (46 ha). Sin embargo, es bastante plausible proponer que, en realidad, falta un espacio hidráulico que no ha podido ser identificado. En el camino real de Xàtiva (la antigua Vía Augusta romana) se encuentra la iglesia de Sant Vicent de la Roqueta, construida inicialmente en el siglo IV, alrededor de la cual parece que existía una pequeña concentración de casas en época andalusí. Tradicionalmente se ha identificado este núcleo con Rajosa, aunque esto es claramente un error. En cualquier caso, aunque no sepamos su verdadero nombre por ahora, es probable que allí existiese un arrabal o alquería semi-urbana, y que debamos añadir su espacio hidráulico (de unas $13 \mathrm{ha}$, por tanto) a la propuesta de reconstrucción del sistema hidráulico de Favara en época andalusí.

Finalmente, nos resta el brazo del molino de les Monges, en el que también hay una diferencia de 8 hectáreas entre las propuestas (32 ha) y las que le tocan proporcionalmente (40 ha). En este caso es más difícil justificar la existencia de otro espacio hidráulico, aunque no puede descartarse de entrada que exista uno al sur de Malilla, pero seguramente se trata de un error en la identificación del perímetro de los dos espacios hidráulicos propuestos para Patraix de Arriba y Altell, pues son de los más dudosos tanto en morfología como en superficie. En cualquier caso, salvo esta discrepancia, que tampoco es demasiado grave, parece bastante plausible que en época andalusí sí existía una proporcionalidad entre la cantidad de agua asignada a cada brazo corrible y la superficie irrigada por ellos.

Por lo que respecta a los brazos no corribles, parece confirmarse que el turno semanal de los brazos finales estaba diseñado para que cada alquería tuviese un día de agua, excepto los sábados, que lo comparten el rāhal de Ibn Mufarriŷ y la alquería de Awraba. Los domingos eran para los Banī Tuzarī, los lunes para los Banī Sīdabī, los martes para al-Hūfar, los miércoles para Manzil Nașr, los jueves para Qat'a ar-Ruaya, y los viernes, el último día, para las dos pequeñas huertas de al-Ba'l. Como puede apreciarse, las superficies regadas cada día son, en general, bastante similares, pues al-Ba'l regaba unas 12 hectáreas, Qat'a ar-Ruaya 16, Banī Tuzarī 16 más, al-Ḥufar 13, y Banī Sīdabī una superficie desconocida pero muy probablemente similar por el espacio existente, de unas 12-15 hectáreas. Las discrepancias son Manzil Nașr con 31 hectáreas, y Awraba más el răhal que sumaban 29. Desde luego estos dos últimos casos son una clara desproporción entre cantidad de tierra regada y horas 
de agua, en relación a los demás brazos que participan del turno semanal, pero debe tratarse de alguna clase de acuerdo, cambio o adaptación en un momento indeterminado, que se nos escapa con la información disponible por ahora.

En total, pues, si entre todos los brazos no corribles suman aproximadamente 119 hectáreas, más la 12-15 de Sedaví, habría más o menos unas 133 hectáreas irrigadas. Como solo deberían regar 106 hectáreas, de acuerdo con los cálculos de proporcionalidad (8/24 partes del agua total), esta la razón por la que es necesario turnarse en el uso de su dotación de agua completa. Además, es evidente que en una acequia tan larga las pérdidas por filtración y evaporación en su tramo final son ya bastante elevadas, y aunque las superficie regada por ellos fuese menor, tampoco tendrían verdaderamente la parte alícuota de agua total que les correspondería, por eso el turno semanal es una solución más eficiente para ellos.

De hecho, sabemos que la combinación de partidores corribles con turnos horarios no era extraña en época andalusí, como demuestra el único caso que conocemos de distribución de agua en un sistema hidráulico de este período, la acequia de Gandía, recogido en un conocido documento de 1244 cuyo funcionamiento es explicado directamente por un săbib alsáqiya. En efecto, en este otro sistema hidráulico existían unos partidores proporcionales de agua continua, que repartían el agua de acuerdo con el tamaño del marco de sus bocas, pero que una vez entraba el agua en cada brazo esta era repartida entre diversas alquerías por turnos de 15 días, llamadas en árabe dawr, que significa "turno". ${ }^{14}$ En este sentido, es posible que en los brazos corribles de Favara se hiciese los mismo, es decir, que en el brazo entrase agua continuamente, pero que una vez dentro esta se turnase de alguna manera entre los espacios hidráulicos que la usaban, aunque esto tampoco puede saberse por ahora.

\section{La proporcionalidad de la acequia de Favara después de la conquista}

A pesar de los problemas para su completa identificación, por no poder ser reconstruidos los espacios hidráulicos andalusíes más cercanos a la ciudad de Valencia, parece plausible que sí existía una proporcionalidad entre cantidad de agua y superficie irrigada antes de la conquista del siglo XIII. Falta saber si esta proporcionalidad siguió existiendo después, con las grandes ampliaciones del espacio irrigado que se hicieron en los años inmediatamente posteriores (Fig. 4). De entrada, es bastante evidente que no pudo existir la misma proporcionalidad, puesto que se construyeron brazos nuevos con sus respectivos partidores de lengua, al mismo tiempo que se aseguró la continuidad de los partidores andalusíes con sus mismas medidas (tal como se establece en el Fuero CXLIII, 4), de manera que la cantidad de agua que tomaba cada brazo quedó automáticamente alterada.

Es posible, sin embargo, que una vez concluido el proceso de ampliación del espacio irrigado, que debió ser muy rápido, los nuevos partidores fuesen construidos de manera que, sin tocar los andalusíes, cada brazo tomase una cantidad proporcional de agua en relación a las nuevas superficies de tierra irrigada por cada brazo. Para comprobarlo, pues, necesitamos saber cuánta agua tomaba y cuánta tierra regaba en aquella época cada brazo. Las partes alícuotas de agua ya las conocemos, pues son las que aparecen en la tercera columna de

\footnotetext{
${ }^{14}$ Este documento no se conserva actualmente, pero fue publicado por el archivero de la Catedral de Valencia Roc Chabàs en 1898 bajo el título Distribución de las aguas en 1244 y donaciones del término de Gandía por Jaime I. Existe una edición facsímil de París-Valencia. He realizado un estudio morfológico inédito de la parte de la huerta de Gandía que describe este documento, y los espacios hidráulicos identificados son similares en forma y tamaño a los identificados hasta ahora en la huerta de Valencia.
} 
la Tabla 2. Falta saber la superficie regada por cada brazo en los primeros siglos después de la conquista.

La reconstrucción del sistema que se muestra en las Figura 2 y 4 corresponde aproximadamente a la superficie irrigada en los siglos XIV-XV, puesto que no incluye los rolls que aún no existían en 1362 (situados antes de Rajosa, y entre l'Hospital y Jesús), ni tampoco los alters, tierras situadas por encima del nivel normal de la acequia a lo largo del recorrido del canal principal, que solo se empezaron a irrigar a partir delos siglos XVI-XVII mediante lo que la documentación llama parades grosses. Aun así, resulta complicado calcular la superficie de espacios hidráulicos tan grandes. Los registros documentales más antiguos de la comuna de Favara son del siglo XVIII, y aunque son muy completos, porque describen cuantas parcelas poseía cada propietario de tierras y qué superficie tenía cada una de ellas, obviamente son muy tardíos. Sin embargo, una de las características de esta comuna es la estabilidad de sus tierras, ya que existía un capítulo en sus Ordenanzas que impedía asociar nuevas tierras de francs $i$ marjals a la comuna, para impedir que adquiriesen derechos de riego y por lo tanto hubiese que repartir el agua entre más regantes. En consecuencia, podemos decir que si descontamos las parades grosses y los rolls que sabemos que fueron añadidos en época moderna, las tierras del resto de brazos deben ser, aproximadamente, las que existían en época bajomedieval.

En la Tabla 4 pueden verse los datos extraídos de un registro de $1741 .{ }^{15}$ En la primera columna aparece la superficie regada por cada brazo en hectáreas, en la segunda columna qué porcentaje representan esas hectáreas del total regado por la acequia, y la tercera columna es el porcentaje de agua que le corresponde a cada brazo según la Tabla 2. Con todo, de la lista de brazos de 1741 hay que restar los rolls y las parades grosses (cifras entre paréntesis), y al igual que en la tabla sobre el período andalusí se han aglutinado los porcentajes de tierra y agua de los brazos del turno semanal (que son los mismos), puesto que no forman parte de la proporcionalidad como los brazos corribles.

Ciertamente resulta un problema no disponer de datos bajomedievales y tener que extrapolarlos del siglo XVIII, aunque seguramente se trata de cifras de superficie que pueden considerarse estables desde la época del Repartiment salvando las ampliaciones conocidas. Del mismo modo, la distorsión provocada por los brazos que no son de lengua supone otro problema, porque consumen agua que no podemos contabilizar, si bien también es salvable. Por lo tanto, los datos de la Tabla 4, con sus defectos, son bastante significativos como para sacar conclusiones fehacientes. Y así lo primero que llama la atención es que los brazos corribles regaban el 60\% de las tierras de Favara, frente al 40\% de los brazos del turno semanal, pero tenían el $80 \%$ del agua, frente al 20\% que les quedaba a los otros. Con todo, esto es algo completamente asumible, porque cada brazo disponía de todo ese $20 \%$ en exclusiva aunque solo fuese un día a la semana. En cualquier caso los porcentajes son tan redondos que ya nos están indicando que sí debía existir una cierta proporcionalidad.

No obstante, si comparamos brazo por brazo el resultado es un poco diferente. Desde luego no existe ninguna proporcionalidad exacta, del nivel de la proporcionalidad que parece existir en época andalusí. Pero ciertamente se trata de una desproporción "moderada", puesto que es evidente que los brazos con una mayor superficie regada recibían, en efecto,

\footnotetext{
${ }^{15}$ Capatró de la Séquia de Favara, 1741. Archivo de la Acequia de Favara, sin catalogar. Agradezco a E. Guinot que me ha facilitado estos datos, e indirectamente a la Comunidad de Regantes de Favara por permitirnos consultar su archivo, incluido el plano de la acequia realizado en 1917. El siguiente registro de tierras conservado es de 1817, muy similar al anterior, pero no se ha utilizado en este trabajo porque la superficie regada ya había empezado a reducirse por el avance urbanizador de la ciudad y el resto de poblaciones de la Huerta.
} 
una mayor cantidad de agua, y los más pequeños recibían menos agua. Además, todos los brazos corribles recibían un porcentaje de agua mayor del porcentaje de tierra que representaban, con la excepción del brazo de Gàbia, que sin duda era el más grande de todos, y por muy poco el brazo de Jesús, que era el segundo más grande.

Tabla 4. Superficie irrigada por la acequia de Favara en 1741 y extrapolación de los siglos XIV-XV

\begin{tabular}{|c|c|c|c|c|}
\hline $\begin{array}{l}\mathrm{N}^{\circ} \text { orden } \\
\text { doc. } 1362\end{array}$ & $\begin{array}{l}\text { Nombre del brazo } \\
\text { s. XVIII-XX }\end{array}$ & $\begin{array}{c}\text { Hectáreas } \\
1741\end{array}$ & $\begin{array}{c}\% \\
\text { Tierras }\end{array}$ & $\begin{array}{c}\% \\
\text { Agua }\end{array}$ \\
\hline 1 & brac de Rajosa & 25 & $1 ’ 94 \%$ & $8 ’ 4 \%$ \\
\hline 2 & brac de l'Hospital-Vintimilla & $140{ }^{\prime} 5$ & $10 ’ 93 \%$ & $14^{\prime} 9 \%$ \\
\hline 3 & rolls de Mateu, la Barca i Roncador & $(100)$ & - & - \\
\hline 4 & braç de Jesús & 200 & $15 ’ 55 \%$ & $14{ }^{\prime} 6 \%$ \\
\hline separado de 5 & rolls de Patraix $i$ de Verdeguer & $(16 ’ 5)$ & - & - \\
\hline 5 & brac de les Monges & 82 & 6'38\% & $11^{\prime} 87 \%$ \\
\hline 6 & fila d'Almela & $19 ’ 5$ & $1 ’ 52 \%$ & $7 ’ 54 \%$ \\
\hline 7 & braç de Gàbia & 242 & $18{ }^{\prime} 82 \%$ & $1432 \%$ \\
\hline 8 & braç Nou & 55 & 4’27\% & $8 ' 64 \%$ \\
\hline \multicolumn{2}{|c|}{ Total brazos corribles } & 764 & $59 ' 41 \%$ & $80 ’ 27 \%$ \\
\hline 9 & braç d'Estadella & $29 ' 5$ & $\uparrow$ & $\bar{\uparrow}$ \\
\hline 10 & brac de Romeu (en parades grosses) & - & & \\
\hline 11 & braç de Sant Jordi & $23{ }^{\prime} 5$ & $\uparrow$ & $\uparrow$ \\
\hline 12 & braç d'Alfafar & 80 & & \\
\hline 13 & brac de la Cadira & 29 & $40^{\prime} 59 \%$ & $199^{\prime} 73 \%$ \\
\hline 14 & fila de Benetússer & 16 & & \\
\hline 15 & braç del Mitjà, la Mola i l'Orba & $102 ’ 5$ & $\downarrow$ & $\downarrow$ \\
\hline 16 & brac de Massanassa & 114 & & \\
\hline 10 & brac de Catarroja-Albal & $127 ’ 5$ & $\downarrow$ & $\downarrow$ \\
\hline \multicolumn{2}{|c|}{ Total Favara siglos XIV-XV } & 1.286 & $100 \%$ & $100 \%$ \\
\hline \multicolumn{2}{|c|}{ roll abans del molí d'Aranda (de Lluna) } & (11) & - & - \\
\hline \multicolumn{2}{|c|}{ roll del moli de Nou Moles } & $\left(4{ }^{\prime} 5\right)$ & - & - \\
\hline \multicolumn{2}{|c|}{ Parades grosses } & $(102)$ & - & - \\
\hline \multicolumn{2}{|c|}{ Total Favara 1741} & 1.520 & - & - \\
\hline
\end{tabular}

Así pues, como conclusión de este trabajo, a pesar de los problemas que puede presentar por la dificultad de acceso a los datos, y a falta de una futura comprobación mediante otros posibles estudios, se puede decir que, probablemente, en época andalusí sí que existió una proporcionalidad directa entre volumen de agua y tierra irrigada. Sin embargo, tras la conquista del siglo XIII, a pesar de mantener intactos los partidores andalusíes, una vez finalizados los cambios y ampliaciones del espacio agrario introducidos por la colonización, no pudo mantenerse esta misma proporcionalidad. Con todo, fue sustituida por una nueva distribución del agua que, aun no siendo exacta ni mucho menos, sí parece guardar una cierta proporcionalidad mal calculada. Además, las nuevas ampliaciones de época moderna ampliarían mucha más las distorsiones en la distribución del agua.

En definitiva, no se puede argumentar que exista una continuidad en el funcionamiento de los sistemas hidráulicos antes y después de la conquista, a pesar de la continuidad física de las principales estructuras como canales de circulación o partidores. Si bien la base legal sobre irrigación introducida en los Fueros (una mezcla de derecho romano y herencia andalusî), auspició la creación de una nueva distribución que sin ser proporcional guardaba una cierta equidad. Probablemente aquí este el origen de buena parte de la conflictividad producida por la distribución del agua de riego en época bajomedieval y moderna. 


\section{Referencias}

Barceló, M., Kirchner, H. y Navarro, C. (1996), El agua que no duerme. Fundamentos de la arqueología hidráulica andalusí, Granada.

Burriel, J. y Rosselló, M. (2002): “La intervención arqueológica en los terrenos del antiguo Hospital General de Valencia”, en M. Rosselló y R. Soriano, Eds., De hospitium, foll i malalts: L'Hospital General de València, Valencia.

Cortés, J. (2001): Liber privilegiorum civitatis et regni Valencie. Jaume I (1236-1276), Valencia.

Escribà, F. y Barceló, C. (1990): La cerámica califal de Benetússer, Valencia.

Esquilache, F. (2011): “L'evolució del paisatge agrari andalusí i feudal de les grans hortes fluvials. Les sèquies de Quart i del Comuner d'Aldaia a l'horta de València", Recerques. Història, economia, cultura, 62: 5-36.

Esquilache, F. (2012): "Perspectivas y problemas en la aplicación de la Arqueología hidráulica a las grandes huertas fluviales. Balance de la investigación en la huerta de Valencia", en A. Castro et al., Eds., Estudiar el pasado: aspectos metodológicos de la investigación en Ciencias de la Antigüedady de la Edad Media, Oxford, pp. 211-221.

Esquilache, F. (en prensa): "The role of the Imazighen tribes in the building of the large irrigated areas in Sharq Al-Andalus. The irrigation canal of the Hawwāras in the Horta of Valencia", en H. Kirchner, Ed., Agrarian Archaeology: Irrigation, drainage, dry agriculture and pastures in Al-Andalus.

Glick, T. (1968): "Levels and Levelers: Surveying irrigation Canals in Medieval Valencia", Technology and Culture, 9: 165-180.

Glick, T. (1970): Irrigation and Society in Medieval Valencia, Cambridge (Mass.).

Glick, T. y Kirchner, H. (2000): "Hydraulic systems and technologies of Islamic Spain: History and archaeology", Working with Water in Medieval Europe, Leiden, Brill, pp. 267-329.

Guichard, P. (1969): "Le peuplement de la région de Valence aux deux premiers siècles de la domination musulmane', Mélanges de la Casa de Velázquez, 5: 103-158.

Guinot, E. (2007): "El repartiment feudal de l'Horta de València al segle XIII. Jerarquització social i reordenament del paisatge rural", en E. Guinot y J. Torró, Eds., Repartiments a la Corona d'Aragó (segles XII-XIII), Valencia, pp. 115-199.

Guinot, E. (2008): "El paisaje de la Huerta de Valencia. Elementos de interpretación de su morfología espacial de origen medieval", Historia de la ciudad, vol. V, Valencia, pp. 116-129.

Guinot, E. y Esquilache, F. (2012): "La reorganización del paisaje agrario en la huerta de Valencia después de la conquista cristiana. El sistema hidráulico y el parcelario de Montcada y Benifaraig en el siglo XIII", Debates de Arqueología Medieval, 2: 229-276.

Guinot, E. y Selma, S. (2008): "L'estudi del paisatge històric de les hortes mediterrànies: una proposta metodològica", Revista Valenciana d'Etnologia, 3: 100-124.

Lewicki, T. (1979): “Hawwāra”, en Encyclopaedia of Islam, Second Edition, t. III, pp. 295-308.

López Elum, P. (2001): Los origenes de los Furs en Valencia y las Cortes en el siglo XIII, Valencia.

Sanchis Ibor, C. (2004): "Les terres de l'Horta de València. Crònica de la recent reducció superficial del regadiu històric", Afers, 47: 111-128.

Torró, J. (en prensa): "Canteros y niveladores. El problema de la trasmisión de la técnicas hidráulicas andalusíes a las sociedades conquistadoras”, Miscelánea Medieval Murciana. 